\title{
Expression of EZH2 in endometrial carcinoma and its effects on proliferation and invasion of endometrial carcinoma cells
}

\author{
YUTING GU*, JING ZHANG* and HUAI GUAN \\ Department of Gynaecology and Obstetrics, Daqing Longnan Hospital, Daqing, Heilongjiang 163000, P.R. China
}

Received May 11, 2017; Accepted September 14, 2017

DOI: 10.3892/ol.2017.7171

\begin{abstract}
Expression of enhancer of zeste homolog 2 (EZH2) has been implicated in cancer pathology, but research on its mechanistic activity is limited. The present study sought to assess the levels expression of EZH2 in patients with endometrial carcinoma (EC) and to explore the effects of EZH2 downregulation on the biological behavior of endometrial carcinoma RL-952 cells. Samples were obtained from a total of 104 patients with EC and an immunohistochemical assay was used to detect the expression of EZH2 in cancer and adjacent tissues. The relationship between the expression of EZH2 and the clinicopathological features was analyzed. Endometrial carcinoma RL-952 cells were transfected with chemically synthesized siRNA to conduct targeting inhibition of EZH2 expression. The expression levels of EZH2 protein were detected by immunoblotting. MTT and Transwell assays were used to detect the changes of cell proliferation and invasion after EZH2 downregulation. Of the 104 cases of endometrial carcinoma samples, 71 cases showed positive expression of EZH2, with an expression rate of $68.27 \%$. In 104 cases of adjacent tissue samples, 25 cases showed positive expression of $\mathrm{EZH} 2$, with an expression rate of $24.03 \%$. The expression of EZH2 in endometrial carcinoma tissue was significantly higher than that in adjacent tissue $(\mathrm{P}<0.05)$. The expression of $\mathrm{EZH} 2$ in endometrial carcinoma tissue was not correlated with the menopausal status and age of patients $(\mathrm{P}>0.05)$, but was correlated with the histological grade, depth of tumor invasion, lymph node metastasis and TNM stage $(\mathrm{P}<0.05)$. The expression of E2H2 was significantly downregulated by si-E2H2 and the proliferation and invasion abilities of cells were significantly reduced after EZH2 downregulation $(\mathrm{P}<0.05)$. EZH2 is closely related to the development of endometrial carcinoma and can enhance the proliferative activity of endometrial carcinoma RL-952 cells and promote cell invasion.
\end{abstract}

Correspondence to: Dr Huai Guan, Department of Gynaecology and Obstetrics, Daqing Longnan Hospital, 35 Aiguo Road, Daqing, Heilongjiang 163000, P.R. China

E-mail: drhuaiguan@hotmail.com; hu272z@163.com

*Contributed equally

Key words: endometrial carcinoma, EZH2, proliferation, invasion

\section{Introduction}

Endometrial carcinoma (EC) is one of the most common malignancies in the female reproductive system. It typically occurs in perimenopausal women approximately 50 years of age. Recent studies have shown that the incidence of EC is rising yearly (1). According to statistical data, the morbidity of EC ranks second among female reproductive tract tumors, second only to cervical cancer (2). It has been found that EZH2 is a core component of the family of Polycomb group proteins (3). Studies have shown that EZH2 has abnormal expression in gastric (4), esophageal (5), liver cancer $(6,7)$ and other malignant tumors and is closely related to tumor growth, development and prognosis. However, there has been very little research on the expression of EZH2 protein in the tissues of patients with EC. Moreover, EZH2 is highly expressed in a variety of tumors and can regulate the expression of genes to promote cell proliferation, invasion and metastasis; therefore, EZH2 may be a potential target for the treatment of EC $(8,9)$. In this study, an immunohistochemical assay was used to detect the expression of EZH2 protein in endometrial carcinoma and adjacent tissues obtained from a total of 104 patients. In addition, the correlation between EZH2 expression and clinicopathological features was analyzed to explore the effects of inhibition of EZH2 expression on the proliferation and invasion of endometrial carcinoma RL-952 cells.

\section{Materials and methods}

Cell line. Human endometrial carcinoma cell line RL-952 cells were purchased from the Shanghai Academy of Life Sciences Cell Bank (Shanghai, China).

Reagents. Lipofectamine 2000 transfection reagent was purchased from Invitrogen (Carlsbad, CA, USA); small interfering RNA (si-RNA) was synthesized by Shanghai Gemma (Pudong New Area, Shanghai, China); rabbit anti-human EZH2 monoclonal antibody and glyceraldehyde-3-phosphate dehydrogenase (GAPDH) antibody were purchased from Abcam (Cambridge, UK); immunohistochemical SP kit, DAB color kit and hematoxylin were purchased from Zhongjin Jinqiao (Beijing, China); horseradish peroxidase conjugated secondary antibody was purchased from Santa Cruz Biotechnology (Dallas, TX, USA); Transwell Chamber was purchased from Corning Inc. (Corning, NY, USA); and CCK-8 
Table I. siRNA-EZH2 primer sequences.

\begin{tabular}{llc}
\hline siRNA & Sense strand sequence (5'-3') & Antisense strand sequence (3'-5') \\
\hline si-EZH2-1 & GCUCCUCUAACCAUGUUUATT & UAAACAUGGUUAGAGGAGCTT \\
si-EZH2-2 & GGAUCACCGAGAUGAUAAATT & UUUAUCAUCUCGGUGAUCCTT \\
si-EZH2-3 & GAGGGAAAGUGUAUGAUAATT & UUAUCAUACACUUUCCCUCTT
\end{tabular}

kit was purchased from Nanjing Kaiji Biological Co., Ltd. (Nanjing, China).

Sample collection. A total of 104 patients admitted to Daqing Longnan Hospital from May, 2014 to June, 2016 with the pathological diagnosis of EC were selected as subjects. All patients underwent total uterine, double attachment resection and pelvic lymphadenectomy. Patients had not received chemotherapy, radiotherapy or biological targeted therapy before surgery. The patients' ages ranged from 31 to 67 years (average age, $47.56 \pm 15.49$ years). According to the degree of pathological differentiation, 38 cases were well differentiated, 34 cases were moderately differentiated and 32 cases were poorly differentiated. According to the revised staging for carcinoma adopted by the 2009 International Union of Obstetrics and Gynecology (FIGO), 26 cases were in stage I, 31 cases were in stage II, 29 cases were in stage III, and 18 cases were in stage IV. Pathological types: endometrial adenocarcinoma was present in 59 cases, clear cell carcinoma in 23 cases and serous papillary carcinoma in 22 cases. A total of 104 corresponding adjacent tissue samples were obtained from the patients. This study was approved by the Medical Ethics Committee of Daqing Longnan Hospital (Heilongjiang, China), and all patients and their families signed the informed consent.

Determination of EZH2 expression in endometrioid adenocarcinoma and adjacent tissues by an immunohistochemical assay. The paraffin embedded tissue blocks of patients with EC were collected and $4 \mu \mathrm{m}$ consecutive paraffin sections were cut and heated at $65^{\circ} \mathrm{C}$ for $2 \mathrm{~h}$. After dewaxing and hydration, an immunohistochemical SP method was used in accordance with the protocol. Sections were incubated with anti-EZH2 primary antibody (1:500) overnight at $4^{\circ} \mathrm{C}$ followed by 3 washes in phosphate-buffered saline (PBS). The sections were then incubated with enzyme-conjugated secondary antibody at $37^{\circ} \mathrm{C}$ for $1 \mathrm{~h}$; after washing, the sections were incubated with diaminobenzidine (DAB) as the chromogen and counterstained with hematoxylin. Assessment of results was as follows: EZH2 positive cells showed brown or yellow granules in the nuclei. Six different fields of view were randomly selected under microscope (Olympus, Tokyo, Japan) at x200 magnification and the result was evaluated according to the percentage of positive cells and the severity of the pigment. First, scoring according to the severity of the pigment was: negative as 0 points; light yellow as 1 point; brown as 2 points; strong brown as 3 points. Second, scoring according to the percentage of positive cells in the total cells was: $0-30 \%$ as 1 point, $30-70 \%$ as 2 points and $70-100 \%$ as 3 points. Two scores were multiplied for each section: 3 points or more represented positive expression; otherwise, the scores represented negative expression.

Transfection of small interfering RNA by cell culture medium. The endometrial cancer RL-952 cells were removed from the $-80^{\circ} \mathrm{C}$ refrigerator and placed in a $37^{\circ} \mathrm{C}$ water bath until they were completely thawed. The cells were then incubated in a $37^{\circ} \mathrm{C}$ incubator and the medium was replaced periodically. Lipofectamine 2000 transfection reagent was used to transfect siRNA-EZH2 three times and the control group siRNAs once into endometrial cancer RL-952 cells, respectively, for 4 samples total. The protocol was performed according to the user manual. Three primers, EZH2-Homo-1741 (si-EZH2-1), EZH2-Homo-803 (si-EZH2-2) and EZH2-Homo-2167 (si-EZH2-3), were designed to ensure the efficiency of the transfection. The sequences are shown in Table I.

Determination of EZH2 protein expression in endometrial carcinoma RL-952 cells by western blot analysis. After transfection, the total protein in the cells was extracted according to the RAPI lysis and extraction buffer manual. Protein concentration was quantified by Coomassie brilliant blue method. A total of $60 \mu \mathrm{g}$ of protein was separated by $10 \%$ SDS-PAGE and the separated protein was transferred to PVDF membrane after $1.5 \mathrm{~h}$ of electrophoresis. The membrane was incubated in $5 \%$ skim milk powder at room temperature for $1 \mathrm{~h}$, and then rabbit anti-human EZH2 primary antibody $(1: 1,500)$ was added and the membrane was incubated overnight at $4^{\circ} \mathrm{C}$. After washing the membrane with PBS, the secondary antibody $\operatorname{IgG}$ $(1: 2,000)$ was added and the membrane was incubated again at $37^{\circ} \mathrm{C}$ for $2 \mathrm{~h}$. ECL was added on the membrane and blots were developed in the dark. Images were recorded with a gel imaging system (Bio-Rad Laboratories, Irvine, CA, USA) and the gray-scale values were calculated. GADPH was used as the internal reference and the ratio of EZH2 to GAPDH protein was interpreted as the relative expression level of EZH2.

Determination of cell proliferative ability by MTT after interference of EZH2 gene. The cells were collected after transfection (control group, cells transfected with control siRNAs; negative control group, normal untransfected cells; si-EZH2 group, cells transfected with si-EZH2-3) and cultured in an incubator. The number of cells was 5,000 in each well, with 5 -wells for each group. After incubation at $37^{\circ} \mathrm{C}$ and $5 \%$ $\mathrm{CO}_{2}$ for $24 \mathrm{~h}, 5 \mu \mathrm{l}$ of $5 \mathrm{mg} / \mathrm{ml}$ MTT was added to each well. After $4 \mathrm{~h}, 200 \mu \mathrm{l}$ of dimethyl sulfoxide (DMSO) was added to each well with shaking for $10 \mathrm{~min}$. The absorbance value of each well at $490 \mathrm{~nm}$ was detected by a microplate reader (BioRad 680). The absorbance values at days 1,2, 3 and 4 were detected by MTT assay and the cell growth curve was plotted. 

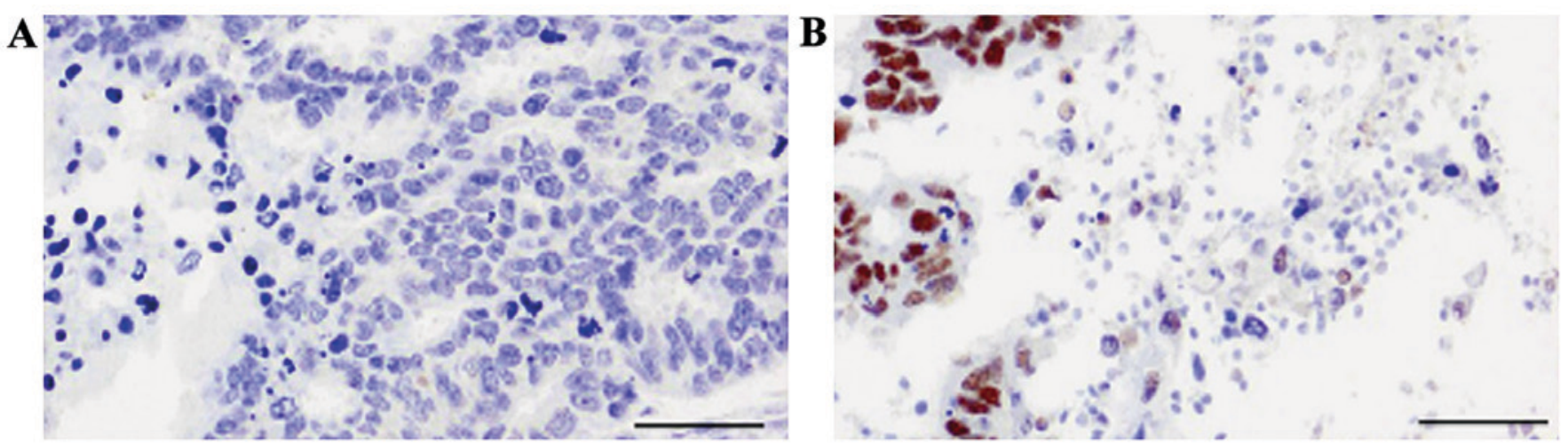

Figure 1. EZH2 in cancer and adjacent tissues. Immunohistochemistry showed that the positive expression of EZH2 in cancer tissue was significantly higher than that in adjacent tissue $(\mathrm{P}<0.05)$. (A) Expression of EZH2 in adjacent tissue; (B) expression of EZH2 in cancer tissue (magnification, $\mathrm{x} 200)$.

$\mathbf{A}$

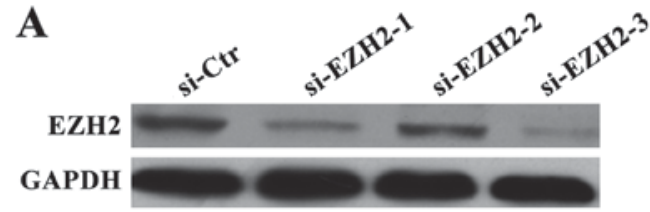

B

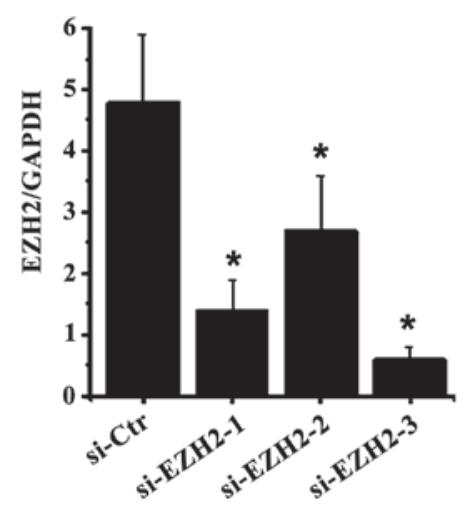

Figure 2. Protein expression before and after interference of EZH2 gene. Western blot analysis showed that the expression of EZH2 protein was sig nificantly inhibited $(\mathrm{P}<0.05)$. (A) The expression of $\mathrm{EZH} 2$ protein by western blot analysis. (B) Analysis for the ratio of optical density of EZH2 to GAPDH (compared with si-Ctr, ${ }^{*} \mathrm{P}<0.05$ ).

Detection of cell invasion ability by a Transwell assay after interference of EZH2 gene. The cells were collected after transfection (control group, cells transfected with control siRNAs; negative control group, normal untransfected cells; si-EZH2 group, cells transfected with si-EZH2-3). Matrigel was diluted to a 1:1 ratio with precooled serum-free culture medium and $20 \mu 1$ of diluted Matrigel was evenly added to the above culture wells made of $8 \mu \mathrm{m}$ polycarbonate membrane at $37^{\circ} \mathrm{C}$ until fully solidified. A total of $200 \mu \mathrm{l}$ cells diluted with serum-free medium $\left(1 \times 10^{5}\right.$ cells $\left./ \mathrm{ml}\right)$ were then added at the lower culture wells and the Transwell plate was incubated at $37^{\circ} \mathrm{C}$ and $5 \%$ $\mathrm{CO}_{2}$ for $24 \mathrm{~h}$. The Transwell plate was removed and fixed with methanol for $30 \mathrm{~min}$; $0.1 \%$ crystal violet was added for $10 \mathrm{~min}$ for staining. After carefully wiping the bottom of the wells with a wet cotton swab to remove Matrigel and non-invasive cells, the wells were observed under an inverted microscope (Leica Microsystems, Wetzlar, Germany). Five fields of view were randomly selected and the cells were counted, with
Table II. Expression of EZH2 in endometrial cancer and adjacent tissues.

\begin{tabular}{lcccc}
\hline & & \multicolumn{2}{c}{ EZH2 expresssion } \\
\cline { 3 - 5 } Group & No. of & & & $\begin{array}{c}\text { Positive } \\
\text { cases }\end{array}$ \\
& - & + & rate (\%) \\
\hline Endometrial cancer tissue & 104 & 33 & 71 & 68.27 \\
Adjacent tissue & 104 & 79 & 25 & 24.03 \\
$\chi^{2}$ & & & 17.861 & \\
P-value & & & 0.017 & \\
\hline
\end{tabular}

the average number of cells interpreted as the cells passing through the basement membrane.

Statistical analysis. Data were analyzed using SPSS 21.0 software (IBM, New York, NY, USA). Measurement data between the two groups were compared by t-test and among multiple groups it was analyzed by the analysis of variance. The enumeration of data among groups was compared by the $\chi^{2}$ test. Differences with a $\mathrm{P}<0.05$ were considered statistically significant.

\section{Results}

Expression of EZH2 protein in the tissues of patients with endometrial carcinoma. Under microscope, EZH2 protein was observed in the nuclei showing brown or yellow particles. In this study, immunohistochemical results showed that, among 104 cases of EC specimens, 71 cases showed positive expression of EZH2, with an expression rate of $68.27 \%$. In contrast, among 104 cases of adjacent tissue, positive expression of EZH2 was evident in 25 cases, with a $24.03 \%$ expression rate. The expression of EZH2 in endometrial carcinoma tissue was significantly higher than that in adjacent tissue $(\mathrm{P}<0.05)$ (Fig. 1 and Table II).

Relationship between the EZH2 positive expression and the clinical characteristics of patients. The expression of EZH2 in EC was not correlated with the menopausal status or age of patients $(\mathrm{P}>0.05)$, but was correlated with the histological 
Table III. Relationship between the positive expression of $\mathrm{EZH} 2$ and the clinical characteristics of patients.

\begin{tabular}{|c|c|c|c|c|}
\hline \multirow[b]{2}{*}{$\begin{array}{l}\text { Pathological } \\
\text { features }\end{array}$} & \multirow[b]{2}{*}{$\begin{array}{l}\text { Total no. } \\
\text { of cases }\end{array}$} & \multicolumn{3}{|c|}{ EZH2 positive expression } \\
\hline & & $\begin{array}{c}\text { No. of } \\
\text { cases }(\%)\end{array}$ & $\chi^{2}$-value & P-value \\
\hline \multicolumn{5}{|l|}{ Menopause } \\
\hline Yes & 64 & $46(71.88)$ & 0.142 & $>0.05$ \\
\hline No & 40 & $26(65.00)$ & & \\
\hline \multicolumn{5}{|l|}{ Age (years) } \\
\hline$\geq 50$ & 80 & $56(70.00)$ & 0.473 & $>0.05$ \\
\hline$<50$ & 24 & $16(66.67)$ & & \\
\hline \multicolumn{5}{|c|}{ Histology grade } \\
\hline $\mathrm{I}$ & 42 & $30(71.43)$ & $13.287^{\mathrm{a}}$ & $<0.05$ \\
\hline II & 30 & $22(73.33)$ & & \\
\hline III & 32 & $19(59.38)$ & & \\
\hline \multicolumn{5}{|c|}{ Depth of infiltration } \\
\hline Shallow & 38 & $24(63.16)$ & $5.692^{\mathrm{a}}$ & $<0.05$ \\
\hline Deep & 66 & $47(71.21)$ & & \\
\hline \multicolumn{5}{|l|}{$\begin{array}{l}\text { Lymph node } \\
\text { metastasis }\end{array}$} \\
\hline No & 58 & $38(65.52)$ & $8.472^{\mathrm{a}}$ & $<0.05$ \\
\hline Yes & 46 & $33(71.74)$ & & \\
\hline \multicolumn{5}{|l|}{ TNM stage } \\
\hline I, II & 42 & $28(66.67)$ & $6.489^{\mathrm{a}}$ & $<0.05$ \\
\hline III, IV & 62 & $45(72.58)$ & & \\
\hline
\end{tabular}

${ }^{a} \chi^{2}$ results indicate that the difference in EZH2 expression for the given variable was statistically significant.

grade, depth of tumor invasion, lymph node metastasis and TNM stage $(\mathrm{P}<0.05)$ (Table III).

Determination of protein expression before and after interference of the EZH2 gene by western blot analysis. As shown in Fig. 2, compared with the control group, the expression of EZH2 in cells was significantly inhibited after the three siRNA-EZH2 samples were transfected into endometrial carcinoma RL-952 cells, in which the inhibition of the third siRNA was the most markedly pronounced.

Effect of the EZH2 gene interference on cell proliferative ability. Compared with the control group, the proliferative ability of the cells was significantly decreased after being treated with siRNA-EZH2-3, and the difference was statistically significant $(\mathrm{P}<0.05)$ (Fig. 3$)$.

Effect of the EZH2 gene interference on cell invasion ability. The Transwell results showed that the number of cells passing through the basement membrane was significantly reduced after interference of the EZH2 gene with siRNA-EZH2-3 (Fig. 4A). The average number of cells in the si-EZH2 group was significantly higher than that in the control group and the negative control group $(\mathrm{P}<0.05)$ (Fig. 4B).

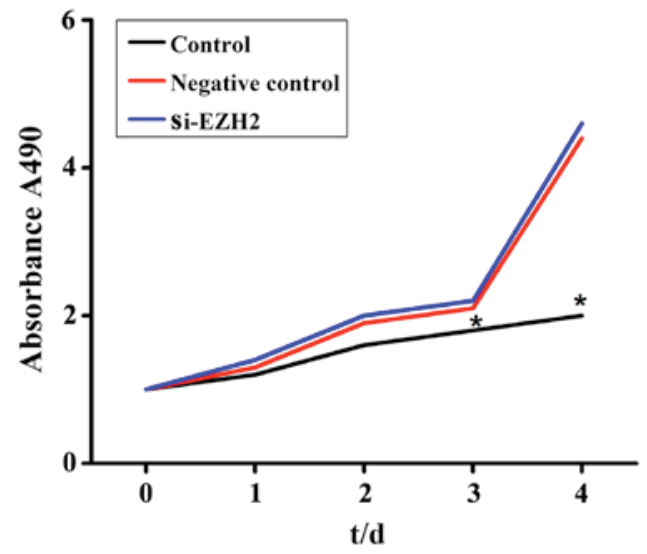

Figure 3. Effect of the EZH2 gene interference on cell proliferative ability. The MTT results showed a significant decrease in cell proliferative ability after siRNA-EZH2-3 interference, compared with the control group and the negative control group $\left({ }^{*} \mathrm{P}<0.05\right)$.
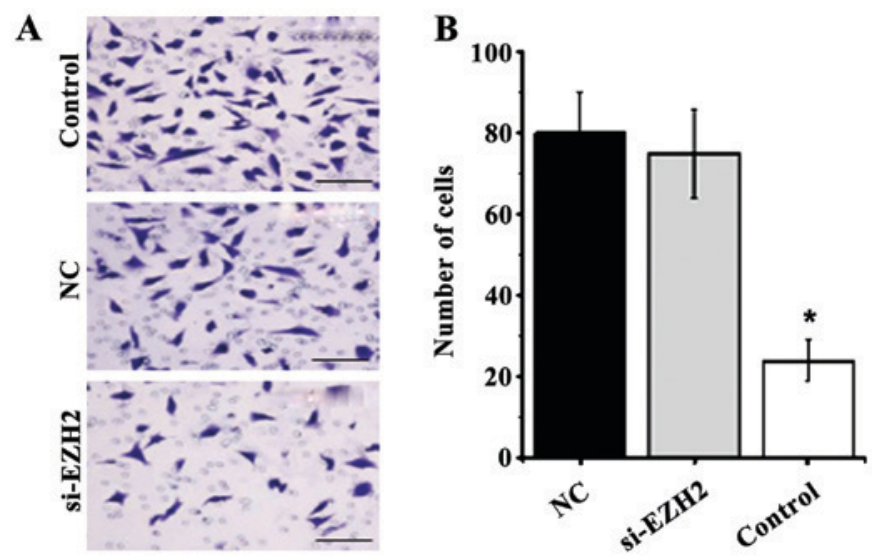

Figure 4. Effects of EZH2 gene interference on cell invasion ability. The Tranwell results showed that the average number of cells in the si-EZH2 group was significantly higher than that in the control group and the negative control group $(\mathrm{P}<0.05)$. (A) Morphology of cells through basement membrane after staining with crystal violet at x400 magnification; (B) analysis of cell counting under a microscope.

\section{Discussion}

Recent studies have found that the EZH2 gene and protein are highly expressed in a variety of malignant tumors, while non-expression or a low level of EZH2 expression is evident in normal or adjacent tissue $(10,11)$. It has been reported that EZH2 was highly expressed in breast (12), ovarian (13), nonsmall cell lung (14), colorectal cancer (15) and other tumor tissues, and the positive expression rates, as determined by immunohistochemical assays, were 71.7, 49.7, 62.3 and $91.9 \%$, respectively. Several researchers world-wide have also reported on the relationship between EZH2 expression and clinicopathological features. Chang et al (16) collected a total of 128 samples from patients with the pathological diagnosis of breast cancer and analyzed the expression of EZH2 in the tissues by immunohistochemical staining. The results showed that the expression of EZH2 in the tissues of breast cancer at stages III and II was $60.9 \%$, which was significantly higher than $18.7 \%$ expression observed in stage I $(\mathrm{P}<0.05)$. Cai et al (17) analyzed 212 biopsies from patients 
with hepatocellular carcinoma and the results showed that diagnostic sensitivity and specificity of EZH2 expression for hepatocellular carcinoma were 95.8 and $97.8 \%$, respectively, suggesting that EZH2 could have an important clinical role in the diagnosis of hepatocellular carcinoma. In addition, they compared the relationship between EZH2 expression and the clinical stage and survival in patients with hepatocellular carcinoma. The results showed that the expression of EZH2 was only correlated with the clinical stage and survival time of patients, but not with age, gender, tumor size, personal history of liver cirrhosis, degree of differentiation or other factors. Rao et al (18) analyzed 179 cases of ovarian cancer samples and the results suggested that highly expressed EZH2 had a significant correlation with the clinical stage and survival rate, but not with the patient's age or gender. A total of 1443 cases of breast cancer tissues were immunohistochemically stained by a concurrent study, and the results showed that high expression of EZH2 was closely related to tumor size and pathological type. Long-term follow-up observation showed that high expression of EZH2 had important clinical value in the prognosis of distant tumor metastasis (19). All these studies indicated that EZH2 was highly expressed in different malignancies, and no significant correlation was observed between its expression and the age or gender of patients. However, EZH2 expression has a certain correlation with the clinical stage and survival time; therefore, it is possible for EZH2 to be a tumor-diagnosed biological marker. The results of this study demonstrated that the expression of EZH2 in endometrial carcinoma tissue $(68.27 \%)$ was significantly higher than that in adjacent tissue $(24.03 \%)(\mathrm{P}<0.05)$. The expression of EZH2 in endometrial carcinoma tissue was not correlated with the menopausal status or age of the patients $(\mathrm{P}>0.05)$ : however, it was correlated with histological grade, depth of tumor invasion, lymph node metastasis and TNM stage $(\mathrm{P}<0.05)$. These correlations are consistent with findings of other research studies (20-22).

EZH2 is highly expressed in EC and has a certain correlation with the clinical stage and survival time of patients, but the exact mechanistic activity of EZH2 in EC is still unclear. Therefore, this study aimed to further explore the possible mechanism of EZH2 in the occurrence and development of endometrial cancer through the interference of the EZH2 gene in endometrial cancer RL-952 cells. We used siRNA to inhibit the expression of the EZH2 gene in endometrial carcinoma RL-952 cells and observed the changes in cellular and biological characteristics. Many studies have shown that EZH2 can promote the proliferation and invasion of endometrial cancer RL-952 cells (23-25), which is similar to its effect on other malignant tumors. Therefore, inhibition of EZH2 can significantly decrease the proliferation of RL-952 cells. The invasion and metastasis of cells is one of the most detrimental features of malignant tumors. According to the tumor cell invasion three-step hypothesis proposed by Liotta et al (26-28), at the molecular level, the process of invasion is divided into three steps of adhesion, degradation and migration: first, tumor cells need contact with the basement membrane. After forming a localized stable tumor, proteases secreted by tumor cells degrade the extracellular basement membrane. Then, tumor cells initiate vascular or lymphatic metastasis under the influence of chemokines. In this study, Matrigel was used to detect the invasive ability of endometrial carcinoma RL-952 cells, and the results showed that the invasive ability of the cells was significantly decreased in vitro after downregulating the EZH2 gene. Wang et al (29) specifically inhibited the EZH2 gene in bladder cancer T24 cells and demonstrated that the invasive ability of T2 4 cells was significantly attenuated. In addition, further studies have reported that the invasive ability of breast cancer cells is significantly reduced upon decreasing the expression of EZH2 gene in the breast cancer cell lines, CAL51 and MDA-MB-231 (30-32). Several studies have shown that, in non-small cell lung (33), cervical (34), gastric cancer (35) and other malignant tumors, the tumor cell invasion ability is significantly inhibited after downregulating of EZH2 gene expression, which corresponds to the results of this study.

In conclusion, EZH2 is closely related to the development of EC and can function as a biomarker for its diagnosis and progression. It can enhance the proliferative ability of endometrial cancer RL-952 cells and promote cell invasion in metastasis. Conversely, its downregulation can inhibit the invasive ability of EC cells, preventing its proliferation.

\section{References}

1. Stålberg K, Kjølhede P, Bjurberg M, Borgfeldt C, Dahm-Kähler P, Falconer H, Holmberg E, Staf C, Tholander B, Àvall-Lundqvist E, et al: Risk factors for lymph node metastases in women with endometrial cancer: A population-based, nation-wide register study-On behalf of the Swedish Gynecological Cancer Group. Int J Cancer 140: 2693-2700, 2017.

2. Hwang JY, Kim DH, Bae HS, Kim ML, Jung YW, Yun BS, Seong SJ, Shin E and Kim MK: Combined oral medroxyprogesterone/levonorgestrel-intrauterine system treatment for women with grade 2 stage IA endometrial cancer. Int J Gynecol Cancer 27: 738-742, 2017.

3. Wu J, Tang Q, Yang L, Chen Y, Zheng F and Hann SS: Interplay of DNA methyltransferase 1 and EZH2 through inactivation of Stat 3 contributes to $\beta$-elemene-inhibited growth of nasopharyngeal carcinoma cells. Sci Rep 7: 509, 2017.

4. Huang M, Hou J, Wang Y, Xie M, Wei C, Nie F, Wang Z and Sun M: Long noncoding RNA LINC00673 is activated by SP1 and exerts oncogenic properties by interacting with LSD1 and EZH2 in gastric cancer. Mol Ther 25: 1014-1026, 2017.

5. Liu F, Gu L, Cao Y, Fan X, Zhang F and Sang M: Aberrant overexpression of EZH2 and $\mathrm{H} 3 \mathrm{~K} 27$ me3 serves as poor prognostic biomarker for esophageal squamous cell carcinoma patients. Biomarkers 21: 80-90, 2016.

6. Zhai R, Tang F, Gong J, Zhang J, Lei B, Li B, Wei Y, Liang X, Tang B and He S: The relationship between the expression of USP22, BMI1, and EZH2 in hepatocellular carcinoma and their impacts on prognosis. Onco Targets Ther 9: 6987-6998, 2016.

7. Zhang H, Yu C, Chen M, Li Z, Tian S, Jiang J and Sun C: miR-522 contributes to cell proliferation of hepatocellular carcinoma by targeting DKK1 and SFRP2. Tumour Biol 37: 11321-11329, 2016.

8. Wang X, Cao W, Zhang J, Yan M, Xu Q, Wu X, Wan L, Zhang Z, Zhang C, Qin X, et al: A covalently bound inhibitor triggers EZH2 degradation through CHIP-mediated ubiquitination. EMBO J 36: 1243-1260, 2017.

9. Jin X, Yang C, Fan P, Xiao J, Zhang W, Zhan S, Liu T, Wang D and $\mathrm{Wu} \mathrm{H}$ : CDK5/FBW7-dependent ubiquitination and degradation of EZH2 inhibits pancreatic cancer cell migration and invasion. J Biol Chem 292: 6269-6280, 2017.

10. Abdelrahman AE, Arafa SA and Ahmed RA: Prognostic value of Twist-1, E-cadherin and EZH2 in prostate cancer: An immunohistochemical study. Turk Patoloji Derg: Feb 4, 2017 (Epub ahead of print). https://doi.org/10.5146/tjpath.2016.01392.

11. Gardner EE, Lok BH, Schneeberger VE, Desmeules P, Miles LA, Arnold PK, Ni A, Khodos I, de Stanchina E, Nguyen T, et al: Chemosensitive relapse in small cell lung cancer proceeds through an EZH2-SLFN11 axis. Cancer Cell 31: 286-299, 2017. 
12. Gong C, Yao S, Gomes AR, Man EP, Lee HJ, Gong G, Chang S, Kim SB, Fujino K, Kim SW, et al; KOHBRA study group: BRCA1 positively regulates $\mathrm{FOXO} 3$ expression by restricting FOXO3 gene methylation and epigenetic silencing through targeting EZH2 in breast cancer. Oncogenesis 5: e214, 2016.

13. Gharpure KM, Chu KS, Bowerman CJ, Miyake T, Pradeep S, Mangala SL, Han HD, Rupaimoole R, Armaiz-Pena GN, Rahhal TB, et al: Metronomic docetaxel in PRINT nanoparticles and EZH2 silencing have synergistic antitumor effect in ovarian cancer. Mol Cancer Ther 13: 1750-1757, 2014.

14. Toyokawa G, Takada K, Okamoto T, Kozuma Y, Matsubara T, Haratake N, Akamine T, Takamori S, Katsura M, Shoji F, et al: Elevated metabolic activity on ${ }^{18} \mathrm{~F}-\mathrm{FDG}$ PET/CT is associated with the expression of EZH2 in non-small cell lung cancer. Anticancer Res 37: 1393-1401, 2017.

15. Yamamoto I, Nosho K, Kanno S, Igarashi H, Kurihara H, Ishigami K, Ishiguro K, Mitsuhashi K, Maruyama R, Koide H, et al: $\mathrm{EZH} 2$ expression is a prognostic biomarker in patients with colorectal cancer treated with anti-EGFR therapeutics. Oncotarget 8: 17810-17818, 2017.

16. Chang CJ, Yang JY, Xia W, Chen CT, Xie X, Chao $\mathrm{CH}$, Woodward WA, Hsu JM, Hortobagyi GN and Hung MC: EZH2 promotes expansion of breast tumor initiating cells through activation of RAF1- $\beta$-catenin signaling. Cancer Cell 19: 86-100, 2011.

17. Cai MY, Tong ZT, Zheng F, Liao YJ, Wang Y, Rao HL, Chen YC, Wu QL, Liu YH, Guan XY, et al: EZH2 protein: A promising immunomarker for the detection of hepatocellular carcinomas in liver needle biopsies. Gut 60: 967-976, 2011.

18. Rao ZY, Cai MY, Yang GF, He LR, Mai SJ, Hua WF, Liao YJ, Deng HX, Chen YC, Guan XY, et al: EZH2 supports ovarian carcinoma cell invasion and/or metastasis via regulation of TGF-beta1 and is a predictor of outcome in ovarian carcinoma patients. Carcinogenesis 31: 1576-1583, 2010.

19. Neusquen LP, Filassi JR, Fristachi CE, Carvalho KC, Dória MT, Soares Júnior JM and Piato JR: EZH2 protein expression and tumor response to neoadjuvant chemotherapy in locally advanced breast cancer. Rev Bras Ginecol Obstet 38: 280-286, 2016.

20. Oki S, Sone K, Oda K, Hamamoto R, Ikemura M, Maeda D, Takeuchi M, Tanikawa M, Mori-Uchino M, Nagasaka K, et al: Oncogenic histone methyltransferase EZH2: A novel prognostic marker with therapeutic potential in endometrial cancer. Oncotarget 8: 40402-40411, 2017.

21. GuoZL, Chen K, Wang XQ and Hu W: Expression and relationship of Ezh2, Runx3 and caspase-3 in endometrial adenocarcinoma. Zhonghua Bing Li Xue Za Zhi 40: 387-391, 2011 (In Chinese).

22. Bachmann IM, Halvorsen OJ, Collett K, Stefansson IM, Straume O, Haukaas SA, Salvesen HB, Otte AP and Akslen LA: $\mathrm{EZH} 2$ expression is associated with high proliferation rate and aggressive tumor subgroups in cutaneous melanoma and cancers of the endometrium, prostate, and breast. J Clin Oncol 24: 268-273, 2006.
23. Ihira K, Dong P, Xiong Y, Watari H, Konno Y, Hanley SJ, Noguchi M, Hirata N, Suizu F, Yamada T, et al: EZH2 inhibition suppresses endometrial cancer progression via miR-361/Twist axis. Oncotarget 8: 13509-13520, 2017.

24. Eskander RN, Ji T, Huynh B, Wardeh R, Randall LM and Hoang B: Inhibition of enhancer of zeste homolog 2 (EZH2) expression is associated with decreased tumor cell proliferation, migration, and invasion in endometrial cancer cell lines. Int J Gynecol Cancer 23: 997-1005, 2013.

25. Zhou J, Roh JW, Bandyopadhyay S, Chen Z, Munkarah AR, Hussein Y, Alosh B, Jazaerly T, Hayek K, Semaan A, et al: Overexpression of enhancer of zeste homolog 2 (EZH2) and focal adhesion kinase (FAK) in high grade endometrial carcinoma. Gynecol Oncol 128: 344-348, 2013.

26. Liotta LA: Adhere, degrade, and move: The three-step model of invasion. Cancer Res 76: 3115-3117, 2016.

27. Liotta LA and Clair T: Cancer. Checkpoint for invasion. Nature 405: 287-288, 2000.

28. Liotta LA and Kohn E: Cancer invasion and metastases. JAMA 263: 1123-1126, 1990.

29. Wang HF, Yang H, Hu LB, Lei YH, Qin Y, Li J, Bi CW, Wang JS and Huo Q: Effect of siRNA targeting EZH2 on cell viability and apoptosis of bladder cancer T24 cells. Genet Mol Res 13: 9939-9950, 2014.

30. Gonzalez ME, DuPrie ML, Krueger H, Merajver SD, Ventura AC, Toy KA and Kleer CG: Histone methyltransferase EZH2 induces Akt-dependent genomic instability and BRCA1 inhibition in breast cancer. Cancer Res 71: 2360-2370, 2011.

31. Moore HM, Gonzalez ME, Toy KA, Cimino-Mathews A, Argani P and Kleer CG: EZH2 inhibition decreases p38 signaling and suppresses breast cancer motility and metastasis. Breast Cancer Res Treat 138: 741-752, 2013.

32. Gonzalez ME, Li X, Toy K, DuPrie M, Ventura AC, Banerjee M, Ljungman M, Merajver SD and Kleer CG: Downregulation of EZH2 decreases growth of estrogen receptor-negative invasive breast carcinoma and requires BRCA1. Oncogene 28: 843-853, 2009.

33. Xia H, Yu CH, Zhang Y, Yu J, Li J, Zhang W, Zhang B, Li Y and Guo N: EZH2 silencing with RNAi enhances irradiation-induced inhibition of human lung cancer growth in vitro and in vivo. Oncol Lett 4: 135-140, 2012.

34. Liu Y, Liu T, Bao X, He M, Li L and Yang X: Increased EZH2 expression is associated with proliferation and progression of cervical cancer and indicates a poor prognosis. Int J Gynecol Pathol 33: 218-224, 2014.

35. Mattioli E, Vogiatzi P, Sun A, Abbadessa G, Angeloni G, D'Ugo D, Trani D, Gaughan JP, Vecchio FM, Cevenini G, et al: Immunohistochemical analysis of pRb2/p130, VEGF, EZH2, $\mathrm{p} 53, \mathrm{p} 16^{\mathrm{INK} 4 \mathrm{~A}}, \mathrm{p} 27^{\mathrm{KIP} 1}, \mathrm{p} 21^{\mathrm{WAF} 1}, \mathrm{Ki}-67$ expression patterns in gastric cancer. J Cell Physiol 210: 183-191, 2007. 